\title{
Modernização agrícola e produção de grãos: um estudo sobre o potencial de contaminação do solo por defensivos agrícolas na região Oeste da Bahia.
}

\author{
Edilene de Jesus Santos ${ }^{1}$
}

\begin{abstract}
Resumo: Este trabalho tem por objetivo analisar o potencial de contaminação do solo pelo uso de defensivos agrícolas na produção de grãos da região Oeste da Bahia. Para tanto, realizou-se o cálculo do Índice de Potencial de Contaminação pelo uso de Defensivos Agrícolas - IDEF para os municípios de Barreiras-BA, São Desidério-BA, Formosa do Rio Preto-BA e Luís Eduardo Magalhães-BA, abrangendo as culturas do milho, da soja, do algodão e do feijão. O estudo parte do entendimento de que é inevitável a expansão da produção de grãos na região Oeste sem comprometer o solo pelo uso de defensivos agrícolas. A partir dessa compreensão, a hipótese básica é de que a necessidade de expandir a produção para atender a demanda de mercado a longo prazo, levará os produtores a aumentarem a produção e a produtividade, e, como consequência, um maior consumo de defensivos agrícolas. Os resultados obtidos sugerem que a soja foi a cultura que apresentou IDEF com valor de 0,20 e a cultura do feijão o menor índice, com valor médio de 0,99 . Conclui-se que o aumento da produção para atender a demanda crescente do mercado internacional e nacional, principalmente da soja, resulta num maior consumo de defensivos e, consequentemente, em um maior potencial de contaminação do solo para a região Oeste da Bahia.
\end{abstract}

Palavras-Chave: Agricultura. Agronegócio. Grãos

\section{Agricultural modernization and grain production: a study on the potential for soil contamination by pesticides in the western region of Bahia.}

\begin{abstract}
This work aims to analyze the potential for soil contamination by the use of pesticides in grain production in the western region of Bahia. Therefore, the calculation of the Contamination Potential Index by the use of Agricultural Defensives - IDEF was carried out for the municipalities of Barreiras-BA, São Desidério-BA, Formosa do Rio Preto-BA and Luís Eduardo Magalhães-BA covering the cultures of corn, soybeans, cotton and beans. The study is based on the understanding that the expansion of grain production in the West region is inevitable without compromising the soil through the use of pesticides. Based on this understanding, the basic hypothesis is that the need to expand production to meet market demand in the long run will lead producers to increase production and productivity, and as a consequence, a greater consumption of pesticides. The results obtained suggest that soybean was the culture that presented IDEF with a value of 0.20 and that the bean culture had the lowest index with an average value of 0.99. It is concluded that the increase in production to meet the growing demand of the international and national market, especially soy, results in a greater consumption of pesticides and, consequently, in a greater potential for soil contamination in the western region of Bahia.
\end{abstract}

Keywords: Agriculture. Agribusiness. Grains.

1 Economista. Mestre em Planejamento e Desenvolvimento Sustentável- NAEA/UFPA e Doutoranda em Economia pela Universidade Federal da Bahia. E-mail: edilenejsantos20@gmail.com. 


\section{Introdução}

O desenvolvimento do sistema capitalista e sua afirmação no Brasil trouxeram reflexos para o setor agrícola que foi pautado nas estratégias vigentes no país para a sua modernização. A modernização transformou as relações no campo, repercutindo na extração da renda da terra e na consolidação de um rural heterogêneo e repleto de especificidades. Dessa forma, para a compreensão do rural contemporâneo no Brasil é preciso levar em consideração os aspectos econômicos, sociais e políticos em que foram estabelecidas as transformações estruturais no setor.

As modificações no meio rural a partir da década de 1970 com os desdobramentos do domínio do capital sobre a agricultura brasileira, são objeto de investigação de diversos autores, dentre eles GRAZIANO DA SILVA (1981); ROMEIRO (1991); HEREDIA et.al. (2010) e DELGADO (2012). A expansão do capital para investimento em áreas de fronteira agrícola possibilitou a ampliação da estratégia de dominação da agricultura empresarial no rural brasileiro, e, concomitantemente a esse processo, percebe-se a concentração não só fundiária, mas também de poder.

Nesta acepção, a expansão das lavouras de commodities como a soja, milho e algodão no país, principalmente nas novas fronteiras agrícolas, como as regiões do Cerrado e a Amazônia, apresenta uma preocupação com o acirramento dos conflitos de interesse que possam surgir a partir da ótica dos atores sociais envolvidos neste processo, aliado à expansão do uso de defensivos agrícolas nas culturas. Observa-se que, à medida que a produção agrícola aumenta, o consumo de agrotóxicos também aumenta, indicando uma relação "químico-dependente" destas lavouras com o uso de agrotóxicos (CARNEIRO et al., 2015; MOREIRA et al., 2012; PIGNATI, 2007; PIGNATI et al., 2014).

Um exemplo da expansão agrícola no Brasil é a região denominada "MATOPIBA", considerada área de fronteira agrícola composta pelos estados do Maranhão, Tocantins, Piauí e Bahia. O MATOPIBA representa atualmente uma área de exploração do capital agrícola que foi intensificada com a entrada da produção de soja, milho e algodão, que redundou no fortalecimento do agronegócio e despontou como referência em tecnologia e modernização agrícola no cenário nacional (BRASIL, 2015). Portanto, é salutar analisar sob a ótica de utilização de defensivos agrícolas a produção de grãos da região Oeste da Bahia, estado integrante desta área de fronteira agrícola.

Partindo do entendimento de que é inevitável a expansão da produção de grãos sem comprometer o solo pelo uso de defensivos agrícolas, o objetivo central do trabalho é analisar o potencial de contaminação do solo pelo uso de defensivos agrícolas na produção de grãos da 
região Oeste da Bahia, por meio do cálculo do Índice de Contaminação por Defensivos Agrícolas -IDEF. A partir dessa compreensão, a hipótese básica é de que a necessidade de expandir a produção para atender a demanda de mercado no longo prazo, levará os produtores a aumentarem a produção e a produtividade, e como consequência, um maior consumo de defensivos agrícolas.

Para tanto, o trabalho encontra-se estruturado em 6 seções. Na primeira seção busca-se realizar uma discussão sobre o cenário e os condicionantes acerca da modernização agrícola e da produção de grãos no Brasil. Na seção seguinte, são apresentados os efeitos ambientais causados pelo uso de defensivos agrícolas. Em seguida, discutem-se as características da produção de grãos e de soja na região Oeste da Bahia. A quarta seção apresenta o conceito e a metodologia do cálculo para a análise do Índice de Contaminação por Defensivos Agrícolas-IDEF. Na quinta seção, realiza-se a discussão dos resultados encontrados e por fim, são apresentadas as considerações finais.

\section{A modernização agrícola e a produção de grãos no Brasil}

O setor agrário no Brasil possui uma participação relevante para a economia do país, sobretudo pela característica agroexportadora que persiste nos dias atuais, em especial quando se observa a pauta das exportações, na qual os produtos agrícolas se destacam entre os produtos mais exportados pelo país. Desse modo, ao longo da história da evolução da agricultura no Brasil, o setor agrário foi e continua sendo alvo de políticas agrícolas com o objetivo de fortalecer as atividades no meio rural.

Desse modo, o Brasil está entre os maiores produtores de grãos do mundo. Em relação à produção de milho, o Brasil ocupa a terceira posição na produção mundial com 101.138.917 t, depois dos Estados Unidos que lidera a produção com 347.047.570 t e da China na segunda posição com 260.957.662 t em 2019 (FAOSTAT, 2020).

No que tange à produção de soja o Brasil, os Estados Unidos e a Argentina são os países que lideram a produção mundial, sendo justamente esses três países os principais fornecedores de soja para o mercado mundial, de modo que a produção conjunta de soja desses países em 2019 chegou ao patamar de 266.326 .463 t, representando $84 \%$ da produção mundial desse grão. O Brasil e os Estados Unidos foram responsáveis por 66\% da produção mundial de soja em 2019 (FAOSTAT, 2020). Ademais, estudos da FAO (2009) indicam a perspectiva de aumento contínuo do consumo de soja e seus derivados ${ }^{2}$, com contribuição importante dos países da

\footnotetext{
2 Dentre os quais a utilização do óleo para a obtenção do biodiesel.
} 
América Latina, por conta da disponibilidade de áreas de terras para expansão das culturas agrícolas.

Contudo, o processo de modernização da agricultura brasileira intensificou-se na década de 1960. O período que inicia em 1965 e estende-se até 1985 é compreendido como um processo desenvolvimento da agricultura capitalista no Brasil e sua integração com a economia urbana e industrial concomitante com o setor externo. Conforme aponta Delgado (2012), a articulação do Estado, por intermédio do Sistema Nacional de Crédito Rural - SNCR, em 1965, direcionou as políticas agrícolas dos institutos criados e propiciou o fomento da produtividade e da inserção capitalista no setor agrícola.

De acordo com Romeiro (1991), o modelo euro-americano de modernização da agricultura $^{3}$ é definido mundialmente nos anos de 1960 como um modelo que provocou modificações profundas na produção agrícola como um todo, sejam nos aspectos econômicos, sociais, políticos e ambientais. Consubstanciado no que denominou-se de Revolução Verde ${ }^{4}$, o modelo proporcionou o avanço das técnicas produtivas que alavancaram e disseminaram mundialmente a exploração da monocultura. Por possuir como base fundamental a utilização intensa de fertilizantes químicos e a seleção de sementes com uma capacidade de resposta considerável ao tipo de fertilização, após a revolução industrial do século XIX e início do século $\mathrm{XX}$, o arquétipo generalizou-se em várias partes do mundo.

A difusão do modelo de produção agrícola consubstanciado em pacotes tecnológicos, encontrou espaço para implantação em diversas regiões do mundo, inclusive no Brasil. Dessa forma, reforça-se neste ponto, a situação de dependência tecnológica e reprodução e um modelo que aprofunda a desigualdade com o mercado externo, pois a produção comercial em grande escala, sobretudo de commodities agrícolas, demanda não só equipamentos e maquinários com tecnologia oriunda de outros países, mas também absorve todo o pacote tecnológico para a produção, o que torna cada vez mais difícil romper com a dependência com o exterior e desenvolver uma produção agrícola mais autônoma (DELGADO, 2012).

O Estado Brasileiro seguindo no bojo das transformações oriundas da industrialização como forma de superar o atraso em relação às economias centrais, no que tange à agricultura, optou por conceder crédito para munir e induzir os agricultores a absorver as tecnologias

\footnotetext{
3 Conforme definido por Romeiro (1991) é o sistema de produção que tornou viável a difusão em larga escala da prática da monocultura (ROMEIRO, 1991, p. 175).

${ }^{4}$ Criada em 1966, por William Gown, a expressão Revolução Verde representa um conjunto de inovações tecnológicas ocorridas na agricultura, a partir da década de 1960, para a obtenção de maior produtividade na produção de alimentos. Por meio do desenvolvimento de pesquisas em sementes, fertilização do solo, utilização de agrotóxicos, mecanização no campo, entre outros insumos industriais. A questão consistia basicamente em aumentar a produção dentro de um dado espaço agricultável, ou seja, intensificar a produção ocupando menor espaço.
} 
derivadas da modernização agrícola (aquisição de maquinário e adubos químicos), de modo que o acesso ao crédito beneficiou e fortaleceu a indústria de fertilizantes, colocando este insumo como integrante da modalidade de crédito para o custeio (DELGADO, 2012). O crédito rural concedido visava aos médios e grandes produtores, aptos a inserir novas tecnologias nas lavouras e garantir o aumento da produtividade.

A década de 1980 marcou o período da implementação de uma política macroeconômica ortodoxa para a economia brasileira com a participação do Fundo Monetário Internacional (FMI), que desarticulou o sistema de crédito rural instaurado no país desde a década de 1960. De acordo com Delgado (2012), o período de transição da agricultura brasileira ocorre concomitantemente ao processo em que "a economia brasileira se defrontará com um longo período de relativa estagnação econômica, em grande medida imposta pelas condições de crise do ajustamento à crise do endividamento externo" (DELGADO, 2012, p.78). Desse modo, a agricultura brasileira obteve um papel central na tentativa de gerir as conjunturas macroeconômicas restritivas impostas no período.

O período de 1983 a 1993 representou, portanto, uma tentativa de resposta à crise de endividamento externo, por meio de saldos comerciais gerados no setor agrícola. O ajustamento externo seria realizado atendendo à geração de saldos comerciais a partir da expansão das exportações de produtos agrícolas e agroindustriais (DELGADO, 2012).

A partir dos anos 2000, na tentativa de resolver as restrições externas impostas pela crise cambial de 1999, a política adotada pelo estado brasileiro pautou-se na readequação das exportações com a maior participação de produtos primários agrícolas e minerais durante o período, consubstanciando numa estratégia de reprimarização dos produtos destinados ao mercado externo.

Aliado a isso, surgem novas formas de estruturação do mercado para a agricultura comercial e a produção de commodities, mediante flexibilização e liberação da comercialização de agrotóxicos, por meio de medidas provisórias e projetos de leis. Estes processos de flexibilização de leis sobre registro, produção, comercialização controle e fiscalização de agrotóxicos encontram-se alinhados aos elementos de apropriação da renda fundiária e promove consequências agrárias e ambientais sobremaneira negativas (DELGADO, 2012).

O "novo" processo de inserção do país no mercado internacional via exportações de commodities, pela expansão comercial do agronegócio, exerce, como aponta Delgado (2012), uma dupla pressão na obtenção de ganhos de produtividade decorrente dos recursos naturais, in verbis:

De um lado a incorporação de novas áreas ao espaço econômico explorado, atual e potencial. Nestes novos territórios, a expansão agrícola se inicia adotando pacote tecnológico preexistente, e exercendo um consumo crescente 
de recursos naturais não produzidos pelo trabalho humano- solos, água, biodiversidade, florestas nativas, luminosidade, condições climáticas, etc. De outro lado, nas zonas de agricultura já consolidada, haverá certamente pressão crescente por aumento da produtividade do trabalho mediante intensificação do pacote tecnológico agroquímico, com consequências ambientais também predatórias sobre o meio ambiente (DELGADO, 2012, p.115).

Dessa forma, a reinserção especializada do Brasil a partir dos anos 2000 ao comércio mundial encontra-se apoiada na tentativa de ganhos de produtividade do setor primário da economia, com origem tanto na exploração de novos recursos naturais (fertilidade natural), como também atendendo à intensificação da utilização do pacote tecnológico preexistente (DELGADO, 2012).

\section{O uso de defensivos agrícolas e seus efeitos ambientais}

O Brasil é um dos maiores produtores agropecuários do mundo e o segundo país que mais exporta esses produtos (IBGE, 2021). E para manter tal produção, o setor agropecuário utiliza intensivamente sementes transgênicas e insumos químicos, como fertilizantes e agrotóxicos.

A extensa área de plantio de lavouras no Brasil, sobretudo de commodities, bem como a técnica e a legislação, isto é, o arcabouço institucional o que pode ser interpretado, por exemplo, como uma expressão de poder político por parte de um determinado grupo social, ou fração do capital, colocou o país no ranking dos países que mais utilizam agrotóxicos no mundo. A imposição da Política da Revolução Verde, dos cultivos transgênicos, o aumento de "pragas" nas lavouras, de créditos agrícolas subsidiados e isenção de tributos fiscais, são fatores que contribuíram para o aumento no consumo de agrotóxicos.

Por conseguinte, o uso de defensivos agrícolas compreende uma categoria especial de insumos, cujo objetivo é evitar perdas de safras causadas pelo ataque de pragas e doenças às culturas. Os defensivos agrícolas como aponta Ruegg et al. (1986), “distribuem-se em três grandes grupos de acordo com a sua destinação específica de uso: inseticidas, que controlam as pragas; fungicidas, que controlam doenças fúngicas, e herbicidas, para o controle de plantas consideradas invasoras". Quanto ao uso de agrotóxicos, Spadotto (1993) observa que o mesmo varia e difere bastante de região para região.

O uso intensivo de agrotóxicos ao atingir indiscriminadamente diversas formas de vida, provoca desequilíbrios no ecossistema local, na medida em que induz ao aparecimento de novas pragas cada vez mais resistentes, além de provocar sérias consequências para a saúde humana (SILVA, 2007). Os danos provocados pelo uso recorrente de agrotóxicos atingem diretamente o 
solo, porque o processo elimina os microorganismos fundamentais à manutenção da fertilidade natural do solo e provoca a sua esterilização, o que termina por afetar a própria produtividade agrícola. Dessa forma, o uso de agrotóxicos incorre num ciclo vicioso de ações que, em longo prazo, podem gerar consequências irreversíveis para o meio ambiente. Conforme apresentado por Silva (2007), destacamos alguns importantes problemas derivados do uso de agrotóxicos, como mostra o quadro 1 a seguir.

Quadro 1. Problemas derivados do uso de agrotóxicos nas lavouras.

\section{Problemas derivados do uso de agrotóxicos nas lavouras}

- Transporte pela atmosfera para áreas distantes afetando regiões habitadas;

- Contaminação da água que por consequência provoca mortandade de peixes e afeta animais aquáticos bem como as populações que vivem no entorno;

- Retenção no solo por longos períodos com a possibilidade de transferência do solo contaminado para as culturas seguintes ou para pastagens, atingindo, portanto, a carne bovina e o leite consumido pelo homem;

- O uso recorrente desenvolve maior resistência nas pragas e necessidade permanente de sintetização de novos produtos para combatê-los;

- Eliminação de insetos úteis ao equilíbrio do ecossistema, como as abelhas e demais polinizadores;

- Efeitos colaterais em plantas, animais e seres humanos.

Fonte: Elaboração própria a partir de Silva (2007).

Conforme exposto no quadro 1, são inúmeras as consequências ambientais acarretadas pelo uso indiscriminado de agrotóxicos nas lavouras. Na pulverização, a título de exemplo, uma parcela dos defensivos aplicados nas lavouras pode ser transportada pelo ar e comprometer a qualidade do ar em áreas distantes, além do uso recorrente favorecer a retenção do produto no solo e dessa forma, eliminar microrganismos que são essenciais e úteis para o equilíbrio do ecossistema local.

Um ponto importante acerca dos agrotóxicos é o que diz respeito à intensidade de uso do princípio ativo por tipo de cultura. Assim, a batata e o tomate destacam-se pelo uso intensivo de agrotóxicos por área cultivada, com 16,6 e $28,2 \mathrm{~kg}$ de fungicidas por hectare/ano, respectivamente. Em termos de tipo de cultura, as que mais utilizam agrotóxicos são: soja, 29,2\% dos herbicidas; batata, 31,1\% dos fungicidas, e citros, com 46,6\% dos inseticidas/acaricidas (PIGNATI et al. , 2017). A soja está entre as culturas que mais utilizam defensivos agrícolas no processo produtivo.

Desse modo, a utilização de defensivos nas lavouras brasileiras foi resultado das políticas agrícolas adotadas no meio rural como tentativa de modernização da agricultura do país; os processos de produção agrícola no Brasil sofreram sensíveis transformações desde a década de 
1960, porém a partir de 1970, o emprego dos insumos modernos foi intensificado. A demanda por insumos e defensivos seria o reflexo das condições favoráveis à obtenção de crédito agrícola, bem como à redução dos custos de empréstimos destinados à compra de insumos produzidos fora da unidade produtiva, com vistas ao aumento da produtividade das culturas em curto prazo (DELGADO, 2012).

Em 1975, os incentivos ao setor industrial promovido pelo Programa Nacional de Defensivos Agrícolas visavam, por um lado, reduzir as importações de agrotóxicos, que em 1974 atendiam a $75 \%$ do consumo desses produtos no país, e, por outro, facilitar o financiamento aos agricultores para a aquisição desses produtos. Tal política mais ativa na década de setenta, chegou a vincular o uso de parte do financiamento obtido à aquisição de insumos modernos (máquinas, fertilizantes, equipamentos e defensivos agrícolas), o que levou a "aplicações sistemáticas de agrotóxicos, mesmo sem a ocorrência de pragas, resultando em pulverização excessivas e desnecessárias” (RUEGG et al, 1986).

Pignati et al (2017) realizaram um estudo sobre o consumo de agrotóxicos no Brasil, que demonstrou que entre os dez municípios que mais consumiram agrotóxicos em 2015, sete deles pertenciam ao estado do Mato Grosso (maior produtor de grãos, inclusive a soja), dois do estado da Bahia e um do estado de Goiás. Entre os municípios do estado do Mato Grosso, Sorriso-MT lidera o ranking com 14,6 milhões de litros de agrotóxicos, sendo seguido por Sapezal -MT com 11,1 milhões de litros.

Embora a aplicação de agrotóxicos também chamados de defensivos agrícolas aumente a produtividade, o seu uso intensivo frequentemente gera um conjunto de externalidades negativas (SOARES; PORTO, 2007). Impactos sobre seres humanos vão desde simples náuseas, dores de cabeça e irritações na pele, até problemas crônicos, como diabetes, malformações congênitas e vários tipos de câncer. Impactos ambientais também são vários, incluindo contaminação da água, plantas e solo, diminuição no número de organismos vivos e aumento da resistência de pestes (SOARES; PORTO, 2007).

Em relação à contaminação do solo, o risco da utilização de agrotóxicos está relacionado ao seu acúmulo a longo prazo, podendo comprometer a absorção de minerais e contribuir para a redução do grau de fertilidade do solo (SOARES; PORTO, 2007). Dessa forma, há uma tendência à intensificação da utilização dos agrotóxicos para manter os níveis de fertilidade do solo e produtividade das lavouras. Diante do exposto, o resultado desse processo pode ser verificado por meio do registro de um número cada vez mais expressivo de estabelecimentos que utilizam agrotóxicos em suas lavouras, sobretudo, nos últimos anos. 


\section{A produção de grãos e de soja na região Oeste da Bahia}

Em relação à produção de grãos no estado da Bahia, a região Oeste tornou-se um dos territórios que a partir da década de 1990 e de forma mais intensiva a partir dos anos 2000, passou a integrar o eixo de reprodução do capital do agronegócio do Brasil. Essa transformação se deu a partir de políticas voltadas para o desenvolvimento das regiões, sendo impulsionadas para a região ao mercado internacional, representando uma mudança significativa na trajetória de desenvolvimento regional e local do Oeste Baiano.

No que tange à produção de grãos, especificamente do milho, soja, algodão e feijão, em 2006, a Bahia obtinha 2.653.660 hectares de área plantada desses grãos e os municípios de Formosa do Rio Preto, Luís Eduardo Magalhães, Barreiras e São Desidério representavam 35,2\% da área plantada no estado (IBGE, 2020). No ano de 2018, a área plantada de grãos no estado correspondia a 2.873.191 hectares, apresentando um aumento de 8\% em relação ao ano de 2006, e a região Oeste já se tornava responsável por $53 \%$ do total da produção de grãos no estado, conforme pode-se observar no gráfico 1.

Gráfico 1. Evolução da área plantada de soja, milho, algodão e feijão no estado da Bahia em municípios* do Oeste baiano de 2006 a 2018.

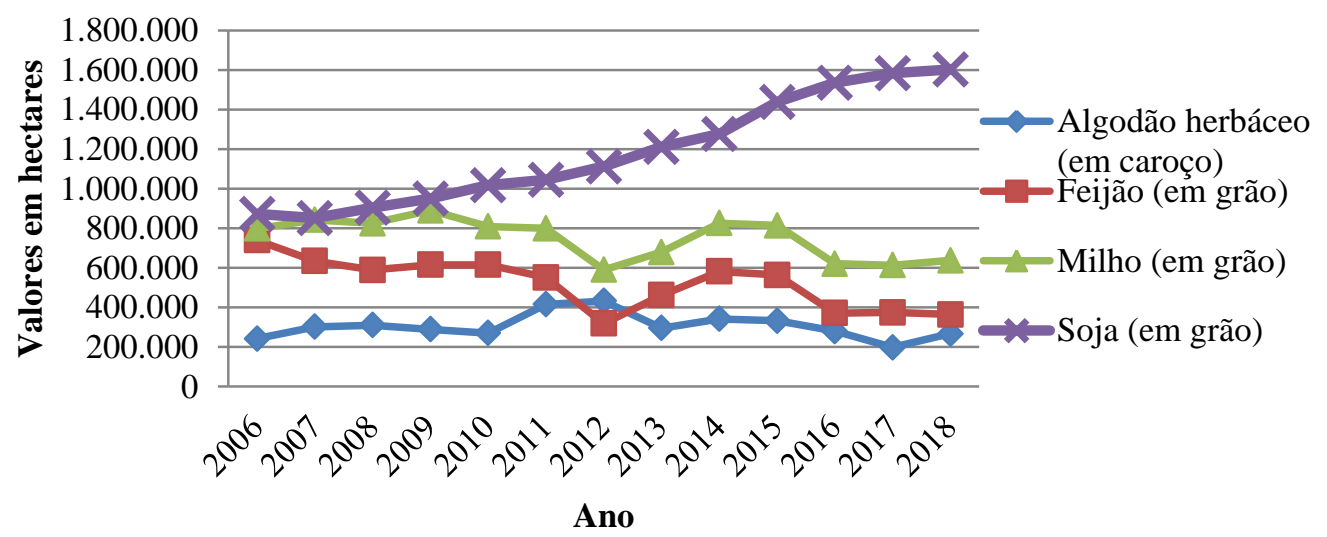

Fonte: Elaboração própria a partir de dados do IBGE/ PAM (2020)

*Os municípios são: Formosa do Rio Preto, Luís Eduardo Magalhães, Barreiras e São Desidério.

De acordo com o exposto no gráfico 1, os dados apontam para uma redução da área plantada de feijão na Bahia em torno de 50\%, saindo de um patamar de 739.781 hectares em 2006, para 364.690 hectares em 2018. O gráfico 1 chama a atenção para o aumento da área plantada de soja, sendo esta a única cultura que apresentou crescimento expressivo no estado entre os anos analisados. Dessa forma, em 2006 a cultura da soja ocupava 872.600 hectares de área plantada no estado e, em 2018, a área ocupada por esta lavoura representava um total de 1.603.203 há, apresentando aumento de 84\%. Os municípios de Formosa do Rio Preto, Luís 
Eduardo Magalhães, Barreiras e São Desidério concentraram 73\% do total da área plantada de soja em 2018 (IBGE, 2020).

O avanço da área plantada de soja no estado da Bahia é uma consequência da expansão da produção em direção a áreas do Cerrado. O desenvolvimento de novas tecnologias criou a possibilidade de produção e exploração do capital em regiões antes improváveis de abrigar atividades agrícolas com alto nível de capital, tecnologia e organização. Portanto, proporcionou a mobilidade do capital global e da força de trabalho para essas regiões.

Em paralelo ao aumento da área plantada, sobretudo de soja, houve uma maior participação de estabelecimentos agrícolas que fizeram uso de agrotóxicos. Os dados do Censo Agropecuário 2017 (IBGE, 2020) para os municípios produtores de grãos da região Oeste da Bahia sobre a utilização de agrotóxicos, demonstraram que os estabelecimentos rurais que mais utilizaram agrotóxicos em suas lavouras foram aqueles que possuíam entre 2.500 a 10.000 hectares de área plantada, sobretudo nos municípios de São Desidério e Formosa do Rio Preto. Os municípios de Luís Eduardo Magalhães, São Desidério e Formosa do Rio Preto foram os municípios que abrigaram os estabelecimentos com maior uso de agrotóxicos com um percentual de $82 \%, 80 \%$ e $76 \%$, respectivamente.

Dessa forma, infere-se que a expansão da área e o tamanho dos estabelecimentos contribuem para uma maior utilização de defensivos agrícolas. Emerge desse fato, a importância de se verificar o potencial de contaminação e as consequências do uso de defensivos agrícolas utilizados na região em estudo.

\section{O Índice de Potencial de Contaminação de uso de defensivos agrícolas (IDEF)}

O Índice de Potencial de Contaminação de Uso de Defensivos Agrícolas- IDEF ${ }^{5}$ utilizado neste trabalho faz parte do grupo de índices de sustentabilidade ambiental proposto por Silva (2007). A base metodológica para a construção do IDEF apresentada por Silva (2007), fundamenta-se na proposta de análise de Pressão-Estado-Resposta ${ }^{6}$-PER adotada pela

\footnotetext{
${ }^{5}$ O Índice de Potencial de Contaminação de uso de defensivos agrícolas- IDEF foi obtido a partir do Índice de Vetores de Degradação - IDEG que compõe o ISAGRI. O IDEG é um índice que mede a de pressão exercida ao meio ambiente através do uso de fertilizantes, uso de defensivos agrícolas e da perda de solo.

6 A metodologia Pressão-Estado-Resposta (PER) adotada pela Organization for Economic Co-operation and Development (OECD) uma das metodologias mais utilizadas e reconhecidas internacionalmente (SILVA, 2007). De acordo com a OECD (1993), a metodologia Pressão-Estado-Resposta (PER) é composta por três indicadores, cada um deles corresponde a uma dimensão ou abrangência de análise. Os indicadores de pressão, por exemplo, mostram os efeitos das ações (ou pressões) do homem sobre o meio ambiente; Os indicadores de estado, por sua vez, descrevem a qualidade do meio ambiente como a qualidade da água, do solo, do ar. E por fim, os indicadores de Resposta auferem a capacidade de recuperação em resposta aos danos. São os indicadores que mostram as medidas (mitigadoras ou protecionistas) tomadas pela sociedade para reduzir ou evitar os impactos negativos da atividade humana sobre o meio ambiente, ou por medidas que permitam parar ou reverter o dano ambiental já inflingido (OECD, 1993).
} 
Organization for Economic Co-operation and Development - OECD (1993) e serviu de suporte para a construção do Índice de Sustentabilidade Ambiental Agrícola-ISAGRI ${ }^{7}$. Neste sentido, o IDEF integra o conjunto de sub-índices pertencente ao índice de Vetores de Degradação-IDEG, que calcula a pressão que uma determinada atividade agrícola incide sobre o meio ambiente, conforme exibido na Tabela 1.

Tabela 1- Subíndices e Indicadores componentes do ISAGRI.

\begin{tabular}{|c|c|c|}
\hline $\begin{array}{l}\text { Índices Parciais / } \\
\text { dimensão }\end{array}$ & Subíndices & Indicadores \\
\hline \multirow{3}{*}{$\begin{array}{c}\text { Índice de Vetores de } \\
\text { Degradação (IDEG) / } \\
\text { pressão }\end{array}$} & $\begin{array}{l}\text { Índice de erosão } \\
\text { (IERO) }\end{array}$ & $\begin{array}{l}\text { Perda de solo } \\
\quad(\mathrm{kg} / \mathrm{ha})\end{array}$ \\
\hline & $\begin{array}{l}\text { Índice de Potencial contaminação } \\
\text { do uso de defensivo agrícola } \\
\text { (IDEF) }\end{array}$ & $\begin{array}{c}\text { Quantidade de } \\
\text { defensivo agrícola } \\
\text { utilizado } \\
(\mathrm{kg} / \mathrm{ha}) \\
\end{array}$ \\
\hline & $\begin{array}{l}\text { Índice de Potencial de contaminação } \\
\text { do uso de fertilizantes (IFERT) }\end{array}$ & $\begin{array}{c}\text { Quantidade de P205 e N } \\
\text { utilizado }(\mathrm{kg} / \mathrm{ha})\end{array}$ \\
\hline
\end{tabular}

Fonte: Elaboração própria adaptado de Silva (2007).

O indicador utilizado, para tanto, é a quantidade de defensivos agrícolas aplicado nas lavouras, por hectare de área plantada. Ademais, o ISAGRI de acordo com Silva (2007, p.119) “apoia-se na dimensão ambiental do conceito de sustentabilidade, em que a qualidade do solo é considerada fator preponderante para a manutenção dos sistemas agrícolas ambientalmente sustentáveis".

Segundo Silva (2007), o ISAGRI considera um sistema agrícola sustentável como aquele que mantém a qualidade do solo em longo prazo, a partir das práticas de manejo consideradas preservacionistas. Dessa forma, a qualidade do solo é definida, por sua vez, pela sua capacidade de exercer suas funções na natureza.

\footnotetext{
7 O Índice de Sustentabilidade Ambiental Agrícola-ISAGRI é uma metodologia composta por um conjunto de índices de mensuração de sustentabilidade ambiental proposto por Silva (2007). Com base na metodologia de Pressão- Estado- Resposta-PER o ISAGRI foi elaborado e dividido em grupos de subindices parciais denominados com base nos seus indicadores, como Índice de Estado de Ecossistema Agrícola - IEA; Indice de Vetores de Degradação - IDEG; e Índice de Medidas de Prevenção e Correção - ICOR (SILVA, 2007).

${ }^{8}$ De acordo com Silva (2007, p.119) "a qualidade do solo é definida, por sua vez, pela sua capacidade de exercer suas funções na natureza." Essas "funções da natureza" referem-se aos serviços ecossistêmicos ao meio ambiente, que a exemplo do solo, oferece o controle da erosão, a ciclagem de nutrientes, a filtragem da água e abastecimento dos aquíferos e por fim, fertilidade para a vegetação. As funções da natureza caracterizam-se segundo (LARSON, PIERCE, 1994; KARLEN et al.,1997) como a habilidade do solo de funcionar como um meio para o crescimento das plantas, regular e compartimentalizar o fluxo de água no ambiente, estocar e promover a ciclagem dos elementos da biosfera e servir como um tampão ambiental na formação, atenuação e degradação de compostos prejudiciais ao ambiente.
} 
Os índices de sustentabilidade que compõem o ISAGRI, por sua vez, consideram um sistema agrícola sustentável, de acordo com Silva (2007), como aquele sistema que mantém a qualidade do solo em longo prazo a partir da utilização de práticas de manejo que podem ser caracterizadas como preservacionistas.

Embora exista uma grande variedade de indicadores que podem ser utilizados numa análise de impacto ambiental provocado pelo uso de defensivos agrícolas, optou-se pela utilização no presente estudo pelo indicador de uso de defensivos agrícolas, seja porque este atende às questões propostas e, igualmente, porque o indicador de uso de defensivos agrícolas mostrou-se como o mais adequado, dentre as opções existentes.

\section{Metodologia}

A base empírica principal do Índice de Potencial de Contaminação de uso de defensivos agrícolas- IDEF foi construída por meio de dados e informações obtidas para a região Oeste da Bahia, e as culturas ${ }^{9}$ agrícolas selecionadas para o estudo foram o milho, a soja, o algodão e o feijão, de acordo com a atividade agrícola desenvolvida na região. Os dados foram analisados para os municípios produtores de grãos do Oeste da Bahia, com enfoque especificamente nos municípios de Barreiras, Formosa do Rio Preto, Luís Eduardo Magalhães e São Desidério, correspondente ao ano de 2018. Para esta análise, foram utilizadas as variáveis de área plantada, quantidade produzida, número de estabelecimentos disponíveis no Panorama Agrícola MunicipalPAM (IBGE, 2020) e no Censo Agropecuário 2017 (IBGE, 2020).

Para elaboração do índice, o ponto de partida teve como base os indicadores de sustentabilidade ambiental agrícola que compõe o Índice de Vetores de Degradação/Pressão, consoante apresentado na Tabela 1, que são transformados em subíndices, cujos valores variam entre zero e um, de tal forma que aqueles valores mais elevados indicam maior sustentabilidade (SILVA, 2007; MARTINS, 2010). Em relação ao IDEF, o indicador utilizado é a quantidade de defensivos agrícolas utilizados por hectares. Para a quantificação desses índices, utilizou-se o pior e o melhor valor possível do indicador ${ }^{10}$, parâmetro igualmente utilizado neste trabalho.

Desta forma, por exemplo, para o índice de potencial de contaminação de uso de defensivos agrícolas, o pior valor considerado foi a quantidade máxima de defensivos utilizada na

\footnotetext{
9 O critério de escolha e definição das culturas selecionadas para a análise deste estudo considerou as lavouras predominantes na região. Portanto, as culturas de soja, milho, algodão e feijão são os cultivos mais comuns e de maior relevância local.

$10 \mathrm{O}$ melhor valor é o valor encontrado com base nos resultados encontrados para as áreas pesquisadas desde que o valor encontrado tenha sido melhor do que aquele encontrado na literatura. O pior valor é aquele observado em termos de sustentabilidade, ou seja, o valor observado mais agressivo ao meio ambiente dentro de todas as observações, para cada variável.
} 
região em estudo ${ }^{11}$. Isso porque a maior quantidade de utilização de defensivos indica maior potencial de contaminação. Com base na média do valor observado para o indicador e nos limites estabelecidos para ele, obteve-se cada índice por meio da expressão matemática 1 (SILVA, 2007; MARTINS, 2010):

Índice $=\left[\frac{(\overline{v o}-p v)}{(m v-p v)}\right]$

Em que :

$\overline{\mathrm{vo}}=$ média do valor observado para o indicador ${ }^{12}$;

$\mathrm{pv}=$ pior valor ${ }^{13} ; \mathrm{e}$

$\mathrm{mv}=$ melhor valor ${ }^{14}$

Conforme discutido por (SILVA, 2007; MARTINS, 2010), a expressão garante que o índice permaneça de zero a um, pelo menos enquanto o valor observado pelo indicador continuar dentro dos limites estabelecidos. Portanto, a aproximação do valor observado em relação ao valor delimitado como melhor, condiciona o índice a aproximar-se de 1 (um), ou seja, avizinha-se da melhor situação, bem como quando o valor observado se aproxima do pior valor, o índice tenderá a zero (pior situação). Desse modo, a equação matemática 1 foi utilizada para quantificar o Índice do Potencial de Contaminação do Uso de Defensivos agrícolas (IDEF).

Nessa pesquisa, o Índice de potencial de contaminação de uso de defensivos agrícolas foi construído utilizando-se a quantidade aplicada de defensivos $(\mathrm{kg} / \mathrm{ha})$ nos municípios que compõem a região Oeste da Bahia. Como defensivos agrícolas incluíram-se as categorias dos pesticidas, acaricidas e fungicidas. Essas informações foram obtidas por categoria de uso e se referem ao total de defensivos agrícolas utilizados nas áreas pesquisadas. Esse pressuposto considera que quanto maior o uso de defensivos agrícolas, maior o seu potencial de contaminação. O melhor e pior valor considerado para o uso de defensivos por cultura estão sintetizados na Tabela 2.

\footnotetext{
${ }^{11}$ Para a análise em curso foram adotadas as médias ponderadas aplicadas a cada tipo de cultivo dentro de cada estado e entre os municípios produtores da região Oeste da Bahia. Esses valores foram comparados por meio de uma expressão matemática, em que se adotou como melhor valor aquele correspondente ao não uso de defensivo agrícola; e o pior valor considerado correspondeu ao valor no qual foi utilizado o maior volume de defensivos entre as culturas avaliadas.

${ }^{12} \mathrm{~A}$ média do valor observado para cada indicador refere-se a média da quantidade de defensivos utilizados em cada Cultura. Para tanto, considerou-se mediante dados da pesquisa para a região Oeste os seguintes valores: $\operatorname{soja}=27$ $\mathrm{kg} / \mathrm{ha} ;$ milho= $17 \mathrm{~kg} / \mathrm{h}$; Feijão $=6 \mathrm{~kg} / \mathrm{ha}$ e algodão $=35 \mathrm{~kg} / \mathrm{ha}$.

${ }^{13}$ Como pior valor, foi adotada a quantidade máxima $(\mathrm{kg} / \mathrm{ha})$ por cultura utilizada nos municípios da região em estudo de modo que, para a soja $=30 \mathrm{~kg} / \mathrm{ha} ;$ milho $=18 \mathrm{~kg} / \mathrm{ha} ;$ Feijão $=9 \mathrm{~kg} / \mathrm{ha}$ e algodão $=40 \mathrm{~kg} / \mathrm{ha}$.

${ }^{14}$ Dada a complexidade no que tange à definição de um valor de referência para o uso de defensivos agrícolas considerou-se para a construção do indicador a não utilização de qualquer defensivo como a situação ideal de sustentabilidade. Nesse sentido, o melhor valor adotado foi de 0 (zero).
} 
Tabela 2. Índice e indicadores do Índice de Potencial de Contaminação de uso de defensivos agrícolasIDEF para a região Oeste da Bahia.

\begin{tabular}{cccc}
\hline & & \multicolumn{2}{c}{ Parâmetros para Cálculo dos Índices } \\
Índice & Indicadores & \multicolumn{2}{c}{ Limites de Indicadores } \\
& & Melhor & Pior \\
\hline Índice de Potencial de & Soja & 30,0 & 0 \\
Contaminação do uso & Milho & 18,0 & 0 \\
de defensivo agrícolas- & Algodão & 40,0 & 0 \\
IDEF & Feijão & 9,0 & 0 \\
\hline
\end{tabular}

Fonte: Elaboração própria, adaptado de Silva (2007).

Isto posto, o Índice de potencial de contaminação do uso de defensivos agrícolas (IDEF) foi obtido a partir dos valores médios da quantidade utilizada de defensivo (kg/ha) por cultura na região estudada. Esses valores são os indicadores de potencial de contaminação e foram utilizados como a média do valor observado (vo) no cálculo do IDEF. Portanto, como descreve a equação 2 abaixo:

$$
\mathrm{IDEF}=\left[\frac{\sum_{i=1}^{4} I Q D E F i}{4}\right]
$$

IQDEF $i=$ Índice de quantidade de defensivo agrícola utilizado $i=1,2,3,4$ : Cultura considerada ( $i=1$ algodão; $i=2$ milho; $i=3$ feijão; $i=4$ soja).

A partir da equação apresentada tornou-se possível calcular o valor que corresponde ao IDEF dos municípios analisados correspondente ao ano de 2018.

\section{Resultados e discussão}

De acordo com a metodologia proposta, o passo seguinte corresponde ao cálculo do IDEF para a região em estudo. Para tanto, os dados expostos na Tabela 3 apresenta a média da quantidade de defensivos agrícolas $(\mathrm{Kg} / \mathrm{ha})^{15}$ utilizada por cultura, bem como os índices de 'potencial de contaminação' de uso de defensivos agrícolas associados, para os municípios produtores de grãos do Oeste da Bahia, os municípios de Barreiras, Formosa do Rio Preto, Luís Eduardo Magalhães e São Desidério, para o ano de 2018. A partir dos dados encontrados, identifica-se qual a cultura que apresenta o maior risco de contaminação do solo por defensivos agrícolas. As culturas cujos valores do IDEF se aproximam de 1 (um) são consideradas com

\footnotetext{
${ }^{15}$ Para o presente estudo foi considerada pelo menos 2 (duas) aplicações por cultura, visto que as culturas analisadas são temporárias. E é comum na região o cultivo de duas safras ao ano.
} 
menor potencial de contaminação, logo, indicam que no seu processo produtivo são utilizados insumos mais agressivos ao meio ambiente, e quanto mais próximos de zero (zero), indicam maior potencial de contaminação. Dessa forma, os dados demonstraram que a lavoura da soja foi aquela que apresentou um maior potencial de contaminação do solo pelo uso de defensivos agrícolas, dentre as culturas observadas em todos os municípios analisados. O valor do IDEF médio encontrado para a soja foi em torno de 0,132 .

Tabela 3. Índice de potencial de contaminação do uso de defensivos agrícolas por uso agrícola dos municípios produtores do Oeste Baiano, 2018.

\begin{tabular}{|c|c|c|}
\hline Cultura & Área (ha) & $\begin{array}{c}\text { Índice de Potencial } \\
\text { Contaminação do uso de } \\
\text { defensivo agrícola } \\
\text { (IDEF) }\end{array}$ \\
\hline \multicolumn{3}{|c|}{ São Desidério (BA) } \\
\hline Algodão & 107.647 & 0,756 \\
\hline Feijão & 11.565 & 0,994 \\
\hline Milho & 59.615 & 0,934 \\
\hline Soja & 392.416 & 0,315 \\
\hline \multicolumn{3}{|c|}{ Barreiras (BA) } \\
\hline Algodão & 22.942 & 0,873 \\
\hline Feijão & 9.300 & 0,989 \\
\hline Milho & 24.109 & 0,935 \\
\hline Soja & 187.451 & 0,202 \\
\hline \multicolumn{3}{|c|}{ Formosa do Rio Preto (BA) } \\
\hline Algodão & 44.518 & 0,883 \\
\hline Feijão & 11.530 & 0,994 \\
\hline Milho & 33.315 & 0,957 \\
\hline Soja & 411.224 & 0,166 \\
\hline \multicolumn{3}{|c|}{ Luís Eduardo Magalhães (BA) } \\
\hline Algodão & 12.100 & 0,925 \\
\hline Feijão & 7.910 & 0,990 \\
\hline Milho & 19.136 & 0,942 \\
\hline Soja & 179.540 & 0,143 \\
\hline
\end{tabular}

Fonte: Elaboração Própria a partir de dados do IBGE/PAM (2020) e resultados da pesquisa.

De acordo com o exposto na Tabela 3, quando a análise é realizada por municípios, o maior valor de IDEF da soja foi encontrado nos municípios de Formosa do Rio Preto e Luís Eduardo Magalhães, com valores de 0,166 e 0,143, respectivamente. No município de Formosa do Rio Preto a cultura da soja ocupou uma área de 411.224 há, o que corresponde a 80\% do total da área plantada no município. Em Luís Eduardo Magalhães a soja ocupou 179.540 há, o que corresponde a $79 \%$ do total de hectares destinados à produção de grãos. 
Os dados apresentados na Tabela 3 tornam-se motivo de preocupação, haja vista que a cultura da soja utiliza cerca de $15 \mathrm{~kg} / \mathrm{ha}$ de insumos e defensivos no seu processo produtivo. Ademais, a soja constitui-se na lavoura com a maior participação em hectares plantados no território em análise. Dessa forma, a cultura da soja apresenta um indicativo de que o seu cultivo pode estar causando efeitos deletérios a toda cadeia trófica ${ }^{16}$ do meio ambiente local, com sérias consequências para a população da região, de modo que ao atingir indiscriminadamente diversas formas de vida, provoca desequilíbrios no ecossistema local, por intermédio da contaminação do solo e da água que afeta os animais aquáticos, bem como as populações que vivem no entorno.

Outro ponto importante a destacar é que a despeito da cultura do algodão utilizar no seu processo produtivo $20 \mathrm{~kg}$ de defensivos por hectare plantado, o IDEF encontrado médio foi em torno de 0,87 , o que indica um menor potencial de contaminação. Como uma das possíveis explicações para tal resultado tem-se a extensão da área plantada, visto que a cultura do algodão ocupa uma área de apenas $12 \%$ do total destinado ao cultivo, já a cultura da soja ocupa $76 \%$ dos 1.584.318 ha destinados para a produção de grãos, portanto, a área plantada de soja é quase 7 (sete) vezes maior do que a de algodão. A partir desses resultados, pode-se inferir que quanto maior a área plantada maior a tendência ao consumo de agrotóxicos e como consequência, maior potencial de contaminação do solo.

Desse modo, foi realizada uma simulação na qual foi construído um cenário hipotético onde a área plantada da soja (cultura com maior área plantada) seria substituída pela cultura do feijão (cultura com menor área plantada), conforme Tabela 4. A simulação foi realizada utilizando o município de São Desidério como parâmetro de análise. Para a construção do cenário realizouse a substituição dos valores correspondentes à área plantada de soja, pela área plantada de feijão, e os resultados estão dispostos na Tabela 4 a seguir.

Tabela 4. Índice de potencial de contaminação do uso de defensivos agrícolas por uso agrícola dos municípios produtores do Oeste Baiano, 2018. (simulação)

\begin{tabular}{lcc}
\hline Cultura & Área (ha) & $\begin{array}{c}\text { Índice de Potencial } \\
\text { Contaminação do uso de } \\
\text { defensivo agrícola (IDEF) }\end{array}$ \\
\hline Algodão & São Desidério (BA) & \\
Feijão & 107.647 & 0,531 \\
Milho & $\mathbf{3 9 2 . 4 1 6}$ & $\mathbf{0 , 6 3 4}$ \\
Soja & 59.615 & 0,874 \\
\hline & $\mathbf{1 1 . 5 6 5}$ & $\mathbf{0 , 9 6 1}$ \\
\hline Algodão & Barreiras (BA) & 0,720
\end{tabular}

16 A cadeia trófica também chamada de cadeia trófica pode ser definida como uma sequência linear da transferência de matéria e energia em um ecossistema, na qual é possível observar uma sequência de organismos servindo de alimento para outros. 


\begin{tabular}{lcc} 
Feijão & $\mathbf{1 8 7 . 4 5 1}$ & $\mathbf{0 , 5 1 0}$ \\
Milho & 24.109 & 0,857 \\
Soja & $\mathbf{9 . 3 0 0}$ & $\mathbf{0 , 9 1 3}$ \\
\hline \multicolumn{3}{c}{ Formosa do Rio Preto (BA) } \\
\hline Algodão & 44.518 & 0,718 \\
Feijão & $\mathbf{4 1 1 . 2 2 4}$ & $\mathbf{0 , 4 4 1}$ \\
Milho & 33.315 & 0,897 \\
Soja & $\mathbf{1 1 . 5 3 0}$ & $\mathbf{0 , 9 4 4}$ \\
\hline \multicolumn{3}{c}{ Luís Eduardo Magalhães (BA) } \\
\hline Algodão & 12.100 \\
Feijão & $\mathbf{1 7 9 . 5 4 0}$ & 0,585 \\
Milho & 19.136 & $\mathbf{0 , 4 1 7}$ \\
Soja & $\mathbf{7 . 9 1 0}$ & 0,859 \\
\hline Fonte: Elaboração Própria a partir de dados do IBGE/PAM (2020) e resultados da pesquisa.
\end{tabular}

Os resultados encontrados na Tabela 4 sugerem que no cenário hipotético 1, no qual a área plantada de soja fosse substituída pela cultura do feijão, ainda assim, a lavoura do feijão apresentava um menor potencial de contaminação de uso do solo, com uma média de 0,50 de IDEF. Os dados apontam que ainda que houvesse uma expansão da área plantada de feijão com aumento em torno de quase $3.000 \%$, o seu potencial de contaminação comprometeria menos o solo do que a cultura da soja. Portanto, a produção de feijão mostrou-se mais sustentável do ponto de vista ambiental, visto que implica em quantidades significativamente menores de aplicação de agrotóxicos e consequentemente, menor contaminação do solo.

Para um cenário 2, no qual a área plantada de feijão fosse ocupada pela soja, o que significaria uma redução considerável na área plantada, o valor do IDEF foi de 0,90. A redução da área plantada contribuiu para um menor índice de potencial de contaminação do solo para a cultura da soja. A partir dos dados encontrados, pode-se inferir que diminuição da área plantada pela soja e outros commodities sendo substituída por outras culturas, como por exemplo, pelo feijão, poderia contribuir para uma agricultura mais sustentável e com menor potencial de contaminação do solo.

Diante dos dados apresentados, percebe-se que o cenário atual coaduna para um aumento da expansão da área plantada de soja, portanto, contribui para a intensificação do uso do solo e degradação ambiental, conforme discutido ao longo da seção.

\section{Considerações finais}

A utilização do cálculo do IDEF, com a mensuração da quantidade de defensivos aplicados nas culturas analisadas, possibilitou avaliar o potencial de contaminação do solo por 
defensivos agrícolas no Oeste Baiano. Por meio do IDEF foram identificadas as culturas com maior e menor potencial de contaminação do solo. Dessa forma, a cultura da soja com um valor médio em torno de 0,132 , foi a cultura que apresentou o maior potencial de contaminação. Já o feijão, com IDEF médio de 0,98, foi a acultura que apresentou menor potencial de contaminação.

Os resultados apontaram para uma redução da área plantada de feijão na Bahia em torno de 50\%, saindo de um patamar de 739.781 hectares em 2006, para 364.690 hectares em 2018, e, paralelo a isso, um aumento na área plantada de soja de 84\% no mesmo período. O aumento da área plantada de soja nos últimos anos reflete a política voltada para a produção de commodities para atender à demanda de mercado, o que ocasiona a ocupação cada vez maior de áreas plantadas por uma cultura intensiva em agrotóxicos, comprometendo o solo com a contaminação pelo uso dos defensivos agrícolas.

Dentre os municípios baianos que integram o ranking de consumo de agrotóxicos estão São Desidério-BA e Formosa do Rio Preto-BA, ocupando o terceiro e sexto lugar, com 10,2 milhões e 8,1 milhões, respectivamente, representando, justamente, os municípios que tiveram suas áreas plantadas de soja expandidas nos últimos 12 anos. Para os municípios em questão, os valores encontrados do IDEF foram de 0,31 e 0,16 , respectivamente, o que indica um potencial elevado de contaminação do solo por defensivos agrícolas.

Dessa forma, os resultados sugerem que a produção de grãos no oeste baiano contribuiu e configurou como um vetor importante para aumento do potencial de contaminação do solo pelo uso de defensivos agrícolas, sobretudo, a produção de soja. Portanto, pode-se inferir que os resultados desse trabalho contribuem para o estudo sobre as análises de contaminação do solo das atividades agrícolas, na medida em que apresenta os resultados da produção de milho, soja, algodão e feijão para o Oeste baiano, numa área de investimento e expansão do agronegócio. Ressalta-se que o cálculo do IDEF ainda não tinha sido utilizado e mensurado até o momento para essa região em específico.

Os resultados obtidos enfatizaram a necessidade do aprofundamento de discussões acerca da produção de grãos na região, associada às questões ambientais, e indicam caminhos para a realização do cálculo do potencial de contaminação de outras lavouras que são cultivadas na região, além de auxiliar na busca de alternativas de cultivos menos agressivos ao ambiente local. Sugere-se, para pesquisas futuras, a realização do cálculo do IDEF para outras lavouras, tanto permanentes quanto temporárias, para evidenciar o impacto de cada uma delas ao meio ambiente, com a finalidade de mapear as áreas com maiores potenciais de contaminação. 


\section{Referências}

ASSOCIAÇÃO BRASILEIRA DE AGRONEGÓCIO - ABIOVE. Informativo ABIOVE sobre sustentabilidade da soja: moratória da soja: relatório do $1^{\circ}$ ano. Disponível em: <www.abiove.com.br/>. Acesso em: 29 abr. 2019.

.Moratória da soja será renovada por mais um ano. Notícias, 17 out. 2011. Disponível em: <www.abiove.com.br>. Acesso em: 3 mar. 2019.

BRASIL. Decreto n ${ }^{\circ}$ 8.447, de 6 de maio de 2015. Diário Oficial da República Federativa do Brasil. Brasília, DF: 6 de mai. 2015.

CARNEIRO, F. F.; PIGNATI, W. A.; RIGOTTO, R. M.; AUGUSTO, L. G. S.;PINHEIRO, A. R. O.; FARIA, N. M. X. et al. Parte 1 - Segurança alimentar e nutricional e saúde. In: CARNEIRO, F. F.; RIGOTTO, R. M.; AUGUSTO, L. G. S.; FRIEDRICH, K.; BURIGO, A. C. (Org). Dossiê ABRASCO: um alerta sobre os impactos dos agrotóxicos na saúde. Rio de Janeiro: ABRASCO; 2015. p. 46-86.

DELGADO, G. C. Do "Capital financeiro na agricultura” à economia do agronegócio: mudanças cíclicas em meio século (1965-2012). Porto Alegre: Editora da UFRGS, 2012.

EMBRAPA. Disponível em:<http://www.embrapa.br> . Acesso em: 5 ago. 2018.

.Tecnologia de produção de soja: região central do Brasil. Londrina, 2004b.

FAO/STAT. Disponível em:<http://faostat.fao.org/faostat. . Acesso em: 22 mai. 2020.

GRAZIANO DA SILVA, J. A modernização dolorosa. Rio de Janeiro. Zahar Editores, 1981.

HEREDIA, Beatriz, PALMEIRA, M; LEITE, S. P. Sociedade e Economia do

“Agronegócio” no Brasil. Revista Brasileira de Ciências Sociais, v.25, n.74, Out/2010.

IBGE. Censo agropecuário 2006. Rio de Janeiro: IBGE, 2006.

IBGE, Instituto Brasileiro de Geografia e Estatística. Panorama Agrícola Municipal-PAM. Disponível em: http://www.pam.ibge.gov.br/bda.>Acesso em: 11 jan. 2020.

LIMA, M. do S. B. de. Políticas públicas e território: uma discussão sobre os determinantes da expansão da soja no sul do amazonas. 2008. 446 f. Tese (Doutorado em Desenvolvimento, Agricultura e Sociedade), Universidade Federal Rural do Rio de Janeiro, Rio de Janeiro, 2008.

LIMA, G. T. Naturalizando o capital, capitalizando a natureza: o conceito de capital natural no desenvolvimento sustentável. Texto para discussão. IE/Unicamp, Campinas, n. 74, jun. 1999. Disponível em: <http://www.eco.unicamp.br/Downloads/

Publicacoes/TextosDiscussao/texto74.pdf>. Acesso em: 17 abr. 2020.

MARTINS, J.J. F. Padrões econômico-ambientais da agropecuária no Estado do Tocantins: estudo comparativo de microbacias correspondentes a três sistemas agrários relevantes. 246 f.: il. ; $30 \mathrm{~cm}$. Tese (Doutorado) - Universidade Federal do Pará, Núcleo de Altos Estudos Amazônicos, Programa de Pós-Graduação em Desenvolvimento Sustentável do Trópico Úmido, Belém, 2010. 
MOREIRA, J.C;PERES. P; SIMÕES, A.C; PIGNATI ;W.A, DORES, E.F;VIEIRA, S; STRUSSMANN, C; MOTT, T. Contaminação de águas superficiais e de chuva por agrotóxicos em uma região de Mato Grosso. Cien Saude Colet 2012; 17(6):1557-1568.

OLIVEIRA, N.P; MOI, G.P, ATANAKA-SANTOS. M; SILVA, A.M.C; PIGNATI ,W.A. Malformações congênitas em municípios de grande utilização de agrotóxicos em Mato Grosso, Brasil. Cien Saude Colet, 2014; 19(10):4123-4130.

PEARCE, D. Environmental economics. Baltimore: The Johns Hopkins University Press, 1993.

PIGNATI, W.A.; MACHADO, J.M.H.; CABRAL, J.F. Acidente rural ampliado: o caso das “chuvas" de agrotóxicos sobre a cidade de Lucas do Rio Verde - MT. Ciência e Saúde Coletiva. Rio de Janeiro, 12 (1): 105-114, 2007.

PIGNATI ,W; OLIVEIRA, N.P; Silva, A.M.C. Vigilância aos agrotóxicos: quantificação do uso e previsão de impactos na saúdetrabalho-ambiente para os municípios brasileiros. Cien Saude Colet 2014; 19(12):4669-4678.

PIGNATI; ;W.A. et al. Distribuição espacial do uso de agrotóxicos no Brasil: uma ferramenta para a Vigilância em Saúde.Ciência \& Saúde Coletiva, 22(10):3281-3293, 2017.

RUEEGG, E. F. et al., O impacto dos agrotóxicos sobre o ambiente, a saúde e a sociedade. São Paulo: Ícone. (Coleção Brasil Agrícola), 1986.

SILVA, L. F. A construção de um índice de sustentabilidade ambiental agrícola (ISA): uma proposta metodológica. Campinas, SP. 2007. 232 f. Tese (Doutorado em Economia Aplicada - área de concentração: Desenvolvimento Econômico, Espaço e Meio Ambiente) Instituto de Economia, Universidade Estadual de Campinas, Campinas, 2007.

SOARES,W.L;PORTO,M.F. Ciência \&Saúde Coletiva,12(1);131-143, 2007.

SPADOTTO,C.A. Impactos ambientais dos agrotóxicos. EMBRAPA - CNPMA. Comunicado Interno, 1993.

SYAMPA, M. Consenso de los commodities y linguajes de valoración em América Latina. Revista Nueva Sociedad. No 244, março-abril de 2013. 